\title{
МНИИРИП должен стать отраслевым центром компетенций
}

\author{
Рассказывает директор ФГУП «МНИИРИП» П. П. Куцько
}

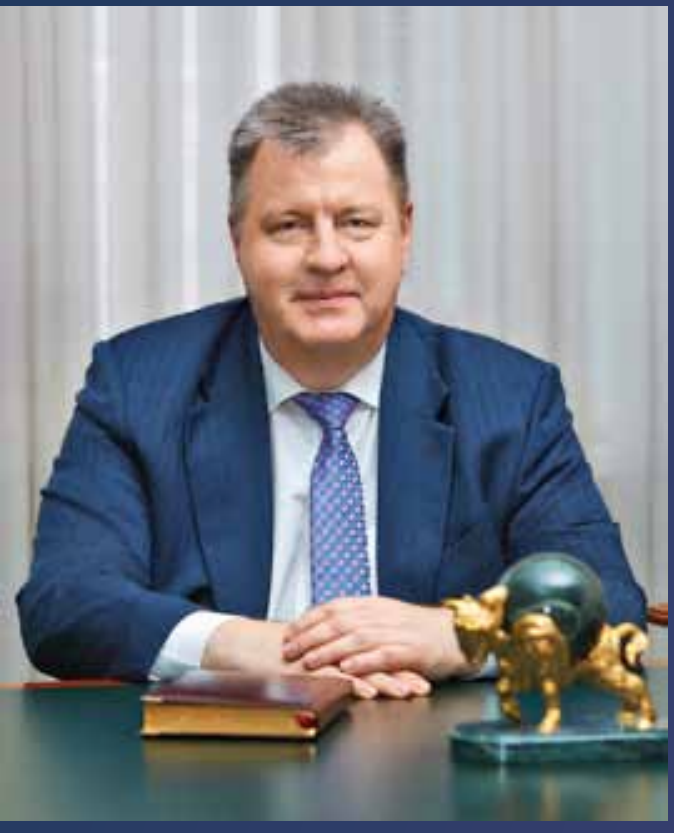

МНИИРИП хорошо известен в нашей отрасли

как институт по исследованиям, испытаниям, сертификации и применению электронной компонентной базы (ЭКБ) для изделий, прежде всего, оборонного назначения. Однако современные условия ставят перед данной организацией новые задачи, в частности по проведению работ в области развития, унификации, стандартизации и применения ЭКБ гражданского и двойного назначения. О планах развития института, существующих проблемах и их решениях, а также о мероприятиях, способствующих развитию отечественной электронной и радиоэлектронной отрасли, нам рассказал директор ФГУП "МНИИРИП», к. т. н. Павел Павлович Куцько.

Павел Павлович, вас знают в отрасли как авторитетного эксперта и руководителя высшего управленческого звена. В январе прошлого года вы были назначены директором ФГУП "МНИИРИП". Вступив в эту должность, на что в работе данной организации вы обратили основное внимание? Как, по вашему мнению, должен меняться институт?

В прошлом году я детально ознакомился с текущим состоянием дел и функционалом МнИИРИП. Были проанализированы и проработаны предложения по повышению эффективности нашей деятельности и дальнейшему развитию института.

Главный вывод - в нынешних реалиях институту необходимо кратно увеличить собственную продуктивность, чтобы она напрямую отразилась на развитии электронной и радиоэлектронной отрасли.

У меня есть любимый фильм “Отроки во Вселенной», снятый в 1974 году. Напомню, действие происходит на далекой планете, где вслед за роботами-исполнителями были созданы роботы-вершители, которые постоянно говорили: «Мы хотим, чтобы вы были счастливы, мы сделаем вас счастливыми". я бы пожелал, чтобы в нашей организации трудилось как можно больше исполнителей, а не «вершителей».

МНИИРИП должен стать ближе к требованиям отрасли, а наше взаимодействие с предприятиями - более регламентированным и менее бюрократизированным. Сотрудничество с бизнесом следует развивать на паритетной основе.

Какие задачи поставлены государством перед вами как директором МНИИРИП?

Сегодня наш институт - головная научная организация Министерства промышленности и торговли России в области развития и применения ЭКБ. Здесь выполняются исследования, осуществляется научно-методическая координация работ по созданию и проведению испытаний изделий ЭКБ, в том числе военного назначения.

Ключевое поручение руководства - расширение функционала МнИИРИП. В ближайшие годы институт должен стать отраслевым центром компетенций и экспертиз по вопросам развития радиоэлектронной промышленности. Поставлены задачи по стратегическому планированию и импортозамещению в части ЭКБ, радиоэлектронных технологий и материалов. 
Кроме того, новые задачи, которые встают перед нашим институтом, определяются главным трендом в отечественном ОПК, который обозначил Президент Российской Федерации,- диверсификацией. В новых условиях МНИИРиП должен работать не только в интересах создания изделий оборонного назначения в части ЭКБ, но и способствовать росту сектора высокотехнологичной продукции гражданского и двойного назначения. На этом направлении будут сфокусированы наши усилия, внимание и энергия.

Вопросы развития радиоэлектронной промышленности выходят за рамки исключительно компонентной базы. Будет ли распространяться расширение функционала вашей организации также и на радиоэлектронную аппаратуру?

Радиоэлектронная аппаратура - важное направление, которое мы развиваем как единый отраслевой центр. Подчеркну, что речь идет об оборудовании гражданского и двойного назначения. Так, в прошлом году МНИИРИП принял участие в нескольких работах в рамках программы «Цифровая экономика Российской Федерации", в частности в разработке критериев отнесения радиоэлектронного оборудования к продукции отечественного производства.

Этот вопрос сейчас приобретает особую актуальность, поскольку является одним из инструментов защиты отечественного производителя в условиях построения цифровой экономики, которые открывают возможности для "перезагрузки» отечественной электронной и радиоэлектронной отрасли. Напомню, что в декабре прошлого года в Новосибирске состоялось совещание по вопросам реализации национального проекта "Цифровая экономика". Минпромторг совместно с Минкомсвязи, Минэкономразвития и другими органами исполнительной власти разрабатывает нормативно-правовые акты, согласно которым госкомпании должны будут закупать оснащение из реестра телекоммуникационного оборудования российского происхождения (ТОРП) либо обосновывать приобретение зарубежной телекоммуникационной аппаратуры.

Однако я убежден, что регулирование обязано охватывать не только сферу закупок телекоммуникационного оборудования, но и приобретение государственными структурами вычислительной техники и радиоэлектронной аппаратуры. Здесь также надлежит определить критерии и установить преференции для отечественных производителей.

К настоящему моменту написано немало различных регламентирующих документов, приказов министерств и федеральных законов, но данные меры малоэффективны. В результате тендеры продолжают выигрывать зарубежные производители. Мы обязаны защитить наш рынок и противостоять экспансии иностранных компаний.

Я считаю, пришло время ужесточать правила игры: вводить новые критерии, вносить изменения в нормативные документы, разрабатывать методики, и наш институт должен стать активным участником этого процесса вместе с федеральными органами исполнительной власти и недавно созданным Консорциумом дизайн-центров российской микроэлектронной промышленности.

\section{В ближайшие годы институт долкен стать отраслевым центром компетенций и экспертиз по вопросам развития радиоэлектронной промышленности}

В частности, мы готовы к ведению реестров радиоэлектронного оборудования отечественного производства различного назначения. Ждем от Министерства промышленности и торговли поручения заниматься данным вопросом на постоянной основе.

Также у нас есть стремление и компетенции решать задачи по декомпозиции радиоэлектронного оборудования гражданского назначения и осуществлять контроль и управление процессом разработки ЭКБ, которая необходима для отечественной аппаратуры. Сегодня крайне важно построить целостную систему связи от компонентов до конечного продукта.

\section{Вы упомянули Консорциум дизайн-центров рос-} сийской микроэлектронной промышленности. Какое участие МнИИРИп принимает в деятельности этой организации?

Развитие данного консорциума с учетом поручения правительства является актуальным и значимым направлением деятельности обновленного МнИИРИП. Сейчас рассматривается вопрос о формировании на нашей базе Центра коллективного пользования, в котором могли бы решаться задачи, обеспечивающие комплексный подход к созданию ЭКБ, такие как объединение библиотек элементов и построение репозитория ІР-блоков, разработанных в рамках государственных программ и проектов; подготовка нормативной документации с требованиями и порядком применения к данным ІР-блокам; обеспечение коллективного пользования программными продуктами для разработки интегральных схем. 
Одним словом, важно построить единую платформу, которая консолидировала бы всех участников процесса.

Продолжая тему разработки ЭКБ, каким образом планируется решать вопрос создания компонентов для аппаратуры гражданского применения, учитывая существенные различия в требованиях, как технических, так и ценовых, к данной ЭКБ и компонентам для изделий оборонного назначения?

В этом отношении базой станет новая концепция стандартизации в части ЭКБ. Проект, разработанный в МНИИРИП, предусматривает сквозную унификацию: от гражданской продукции до ЭКБ с различными требованиями к применению. Образно говоря,

\section{Наша задача - объединить интересы} производителей, изготовителей и поставщиков на едином онлайн-ресурсе
"ЭКБ МАРКЕТ". Сейчас на площадке
зарегистрировано более 700 участников

есть ядро - ЭКБ, а дополнительные требования могут быть сформированы для военной, космической, атомной промышленности и других отраслей. В результате мы сможем учитывать потребности всех потенциальных потребителей, варьировать параметры и стоимость ЭКБ. Эти факторы важны для применения и повышения конкурентоспособности изделий российских производителей на внутреннем рынке.

\section{Значит, появится необходимость в разработке} новых нормативных документов?

На практике все к этому идет. У нас стандартизация ЭКБ в достаточно запущенном состоянии. До сих пор действуют ГОСТы, введенные еще в 1990-2000-х годах. Например, последний комплекс государственных военных стандартов был выпущен в 1998 году. А стандарты должны обновляться каждые пять лет. Именно такой принцип был заложен изначально. Мь по большому счету руководствуемся ГОстами с требованиями и нормами к простейшим микросхемам, таким как триггеры, выпуская сложнейшие микропроцессоры, основанные на технологиях, которые во времена разработки этих стандартов считались фантастическими.

В нашей стране курс на импортозамещение декларируется с 2014 года. В начале 2019 года вы как эксперт могли бы подвести определенные итоги реализации данной программы?

На данный момент я могу оценить только промежуточные итоги. Есть понимание, что импортозависимость снижается, использование отечественной ЭКБ в аппаратуре неуклонно растет.

Электронная промышленность быстро эволюционирует. Никто не препятствует и не будет препятствовать тому, чтобы наши инженеры-конструкторы, создающие перспективную аппаратуру, использовали открытия мировой науки. Однако мы должны осознавать, что существуют направления в электронной аппаратуре, которые напрямую связаны с безопасностью нашего государства. Такие разработки необходимо обеспечивать отечественной ЭКБ в полной мере: в этих областях мы не можем зависеть от иностранных производителей, тем более в условиях действующих санкций.

За последнее время многое сделано. В частности, с 2015 года была запланирована постановка более 300 ОКР по созданию изделий для замены ЭКБ иностранного производства. Эта работа практически выполнена. На данный момент завершено формирование тематик по плановому импортозамещению ЭКБ, рекомендованной к применению при разработке, производстве и эксплуатации вооружения, военной и специальной техники. В 2018 году мы планово приступили к внедрению отечественной ЭКБ в радиоэлектронную аппаратуру.

Я верю, что нам под силу решить поставленную государством задачу. Убежден, что в этом деле нам помогут и такие новые инструменты, как консорциум дизайн-центров и созданная в прошлом году нашим институтом онлайн-площадка «ЭКБ МАРКЕТ».

В марте упомянутая вами площадка "ЭКБ МАРКЕТ", можно сказать, отмечает свой первый день рождения: вы выступили с предложением о ее создании год назад. Каких результатов удалось достичь к настоящему моменту и какие преимущества площадка предоставляет участникам российской электронной и радиоэлектронной отрасли?

Да, я выступил с предложением о создании торгово-информационной платформы для ЭКБ отечественного производства в марте 2018 года на организованной МНИИРИП при поддержке Минпромторга России научно-технической конференции "Актуальные вопросы поставок изделий ЭКБ отечественного производства. Импортозамещение и обеспечение качества». С тех пор мы последовательно идем к поставленной цели.

Наша задача - объединить интересы производителей, изготовителей и поставщиков на едином 
онлайн-ресурсе "ЭКБ МАРКЕТ». Сейчас на площадке зарегистрировано более 700 участников.

Функционал платформы обеспечивает пользователям сайта доступ к актуальному каталогу отечественной ЭКБ, который был разработан МНИИРИП. Здесь же они найдут информацию об изготовителях и их контактные данные. В рамках одного интерфейса обеспечен доступ к исчерпывающей информации о разработанной отечественной ЭКБ. Реализован механизм сравнительного анализа идентичных компонентов: можно сопоставить изделия различных производителей и понять, как они соотносятся с импортными аналогами.

Сейчас данные открыты для всех зарегистрировавшихся на площадке, но в ближайшем будущем появятся также разделы с ограниченным доступом. Как будет пополняться наша база - вопрос открытый.

Мы готовы к конструктивному диалогу со всеми участниками отрасли и приглашаем на площадку всех потребителей ЭКБ отечественного производства и российских производителей радиоэлектронной аппаратуры.

Надеюсь, к формированию площадки «ЭКБ МАРКЕТ» подключится государство, поможет с финансированием наиболее важных для отрасли сегментов онлайн-платформы.

Помимо предоставления данных об отечественной ЭКБ и ее изготовителях, какие возможности площадки "ЭКБ МАРКЕТ" вы выделили бы как наиболее важные для содействия применению российских компонентов в новых разработках?

Одна из важнейших причин того, что сейчас российскими разработчиками активно применяется ЭКБ иностранного производства и что так непросто идет процесс ее замещения отечественными электронными компонентами, заключается в том, что математические модели зарубежных компонентов изначально заложены в САПР, а модели российской ЭКБ отсутствуют. В результате инженерам-разработчикам при проектировании очень сложно применить определенный отечественный компонент. Как только появятся наши математические модели, различий в применении ЭКБ, изготовленных в России и за рубежом, не будет. В этом и заключается паритет, который станет мощным толчком для использования наших чипов в радиоэлектронной аппаратуре.

Хочу обратить внимание на то, что уже сейчас имеющийся функционал позволяет инженерам-разработчикам выгружать с онлайн-площадки данные моделей компонентов в свои САПР. Мы начинаем размещать математические модели поставляемой ЭКБ отечественного производства, предлагать опции по испытаниям на надежность и проверке на контрафактную продукцию.

Какие инструменты предусмотрены для получения обратной связи от отрасли по работе "ЭКБ МАРКЕТ"?

У нас сформирована рабочая группа, которая постоянно находится на связи с потребителями и изготовителями изделий. Мы используем все отрас-

\section{Интегрированный центр испытаний ЭКБ и РЭА создается в целях устранения существующих проблем и противоречий в области испытаний ЭКБ и радиоэлектронной аппаратуры}

левые площадки: круглые столы, конференции, консорциумы для обсуждения функционала проекта «ЭКБ МАРКЕТ» - и призываем всех участников процесса к открытому диалогу и взаимодействию. Вносите конкретные предложения, замечания, помогающие устранить недостатки и преодолеть проблемы в работе платформы.

Какие задачи возложены на интегрированный центр испытаний, который также будет развиваться на базе МнИирип?

Интегрированный центр испытаний ЭКБ И РЭА создается в целях устранения существующих проблем и противоречий в области испытаний ЭКБ и радиоэлектронной аппаратуры. В МНИИРИП сосредоточены сведения о наличии технологического оборудования, оснастки и загруженности по всем испытательным центрам, расположенным в различных регионах России. Мы стремимся организовать для отечественных предприятий справочный онлайн-ресурс, который обеспечивал бы оперативной информацией о работе центров по проведению испытаний ЭКБ и радиоэлектронной аппаратуры.

Планируем разместить данный сервис на площадке "ЭКБ МАРКЕТ», которая объединит информационные ресурсы радиоэлектронной отрасли. Здесь пользователи смогут найти ответы на все свои вопросы, касающиеся полного жизненного цикла ЭКБ.

В нашей стране действует несколько систем добровольной сертификации эКБ на коммерческой основе. Неоднократно звучало мнение о том, что 
это создает неудобства для производителей эКБ, дезориентирует их. Решается ли этот вопрос?

Могу сказать, что в 2018 году многое было сделано для сближения позиций разных систем добровольной сертификации, которые работают в области ЭКБ. Однако существует и другая проблема: некоторые из этих систем не обладают должной квалификацией и даже не аккредитованы на сертификацию ЭКБ, но все равно выдают сертификаты.

По большому счету, даже в системе сертификации "Электронсерт", учрежденной при МнИИРИП, есть что совершенствовать в области повышения качества работы экспертов.

Сейчас в МНИИРИП идет реорганизация данной системы. Мы планируем обновить штат: привлечь молодых независимых экспертов со свежим, объективным взглядом. Результаты наших аудитов должны стать максимально прозрачны, свободны от предвзятости, в том числе от коррупционной составляющей.

\section{Призываем представителей} федеральных органов исполнительной власти, предприятий, потребителей, квалифищированных поставщиков к общению в онлайн-режкиме на наших площадках

Раз зашла речь о привлечении молодых экспертов, насколько сложно найти квалифицированные кадры?

Скажу так: десять специалистов найти несложно. Других нужно воспитывать, применяя в том числе и командные методы. Планируем, что в МНИИРИП каждый отдел определит минимум по два сотрудника с профильным образованием, которые пройдут обучение по программе сертификации. Параллельно наши эксперты познакомятся со всеми имеющимися в стране технологическими процессами на предприятиях-производителях ЭКБ и состоянием дел в этих организациях. Такой подход позволит обеспечить как профессиональный, так и карьерный рост квалифицированных сотрудников в институте: от руководителей отделов до начальников управления и выше.

Вы сказали, фактически, об использовании внутренних ресурсов. А как решается в МНИИРИП вопрос с кадровым пополнением?

У нас подписаны договоры с рядом ведущих институтов о целевом обучении студентов с последующим трудоустройством в нашей организации. Мы также взаимодействуем с руководителями ведущих высших учебных заведений, которые готовят специалистов в области разработки, производства ЭКБ и радиоэлектронной аппаратуры. Стремимся активнее развивать партнерские отношения с представителями высшей школы: увеличивать квоты, проводить ознакомительные семинары.

С вашим приходом в МНИИРИП в институте стало активно развиваться такое направление, как отраслевые конференции, одной из которых стало уже упомянутое мероприятие, положившее начало истории "ЭКБ МАРКЕТ". Какие практические вопросы помогают решать конференции, проводимые МнИирип?

Когда мы решили проводить конференции, поставили перед собой задачу - обсуждать только такие актуальные вопросы и проблемы, которые ранее не поднимались на других отраслевых площадках. Так, темой первого мероприятия стало создание торгово-информационной площадки, второго - организация интегрированного испытательного центра.

Мы учитываем ту важную роль, которую сегодня играет МнИИРИП в жизни радиоэлектронной промышленности в части применения ЭКБ военного назначения. Понимаем, что у руководителей и специалистов предприятий появляется множество актуальных вопросов по регламентам, подписанию тех или иных документов, решений, протоколов и т.д. Такие проблемы и обращения результативнее всего решаются именно на форумах МНИИРИП. Опыт первых двух конференций показал, что участники отрасли крайне заинтересованы во взаимодействии с нашим институтом, который работает под эгидой Минпромторга России.

Любопытный факт, о котором хотелось бы рассказать. Мы постоянно призываем представителей федеральных органов исполнительной власти, предприятий, потребителей, квалифицированных поставщиков к общению в онлайн-режиме на наших площадках. Однако по-прежнему самое продуктивное взаимодействие происходит в рамках конференций. Непосредственное общение экспертов и игроков рынка позволяет решать самые сложные и актуальные вопросы, которые накапливались не один год.

Поэтому я в очередной раз призываю наших партнеров не собирать возникающие трудности "про запас", а в процессе ежедневной работы решать их посредством наших онлайн-ресурсов.

Спасибо за интересный рассказ.

С П. П. Куцько беседовали Г. Ф. Куликова и Ю. С. Ковалевский 